\title{
CARTAS A LA DIRECTORA
}

\section{Señoras y Señores,}

Permitan Vds. unas notas respecto de! trabajo "Circuitos Eléctricos", en En. señanza de las Ciencias, $6(1988) n^{\circ} 3$.

1. ¿Por qué piensan los autores que e! campo elécttico sea demasiado kabstracto»? Una cosa que no es visible no es necesariamente abstracta. Una esfe. ra de influencia, una aura, es un concepto bien conocido en la vida cotidiana (la «Lebenswelt»).

2. El concepto de la corriente eléctrica como "una explicación del modelo en que se transporta la energian es muy limitado. En el fondo se necesita una concepción provisional del campo eléc- trico, pues sin eso es difícil compren. der en qué modo los electronos "saben" cómo distribuir la energía en el circui. to. En caso no estacionario el transporta de la energía por la corriente es im. posible. Piénsese en la corriente altcrna: los electronos apenas cambian sus lugares. Piénsese, además, en una capacidad alta ( $1 \mathrm{~F}$ ): ¿Cómo transportan los electronos la energía a través de ese espacio, de un tado al otro? Es fácil ha. cer experimentos de ese tipo. Por eso la pregunta didáctica es si es oportuno enseñar inicialmente conceptos muy limitados y sustituirlos más tarde por conceptos más generales en situaciones más complejas.
3. ¿Es razonable realizar estudios empíricos sin consenso sobre preguntas de ese tipo? Pienso que la razón por lo que no hay progreso sustancial en la didáctica empirica puede ser hallado en la falta de consenso respecto de preguntas didácticas fundamentales.

P.S. Por favor, ¿transmitirian Vds. estas notas a los autores del trabajo?. Gracias.

Prof. W. Jung Johann Wolfgang Goethe-Universität Frankfurt am Main 